\title{
A Class of Methods for the Analysis of Blade Tip Timing Data from Bladed Assemblies Undergoing Simultaneous Resonances-Part II: Experimental Validation
}

\author{
J. Gallego-Garrido,, ${ }^{1}$ G. Dimitriadis, ${ }^{2}$ I. B. Carrington, ${ }^{2}$ and J. R. Wright ${ }^{2}$ \\ ${ }^{1}$ Experimental Vibrations, Rolls-Royce PLC, P.O. Box 31, Derby DE24 8DJ, UK \\ ${ }^{2}$ School of Mechanical Aerospace and Civil Engineering, The University of Manchester, \\ Simon Building, Oxford Road, Manchester M13 9PL, UK
}

Received 6 March 2006; Revised 17 November 2006; Accepted 2 January 2007

Recommended by Eric Maslen

\begin{abstract}
Blade tip timing is a technique for the measurement of vibrations in rotating bladed assemblies. In Part I of this work a class of methods for the analysis of blade tip timing data from bladed assemblies undergoing two simultaneous synchronous resonances was developed. The approaches were demonstrated using data from a mathematical simulation of tip timing data. In Part II the methods are validated on an experimental test rig. First, the construction and characteristics of the rig will be discussed. Then, the performance of the analysis techniques when applied to data from the rig will be compared and analysed. It is shown that accurate frequency estimates are obtained by all the methods for both single and double resonances. Furthermore, the recovered frequencies are used to calculate the amplitudes of the blade tip responses. The presence of mistuning in the bladed assembly does not affect the performance of the new techniques.
\end{abstract}

Copyright (c) 2007 J. Gallego-Garrido et al. This is an open access article distributed under the Creative Commons Attribution License, which permits unrestricted use, distribution, and reproduction in any medium, provided the original work is properly cited.

\section{INTRODUCTION}

The general characteristics of blade tip timing (BTT) as a method for measuring vibrations in rotating bladed assemblies have already been discussed in Part I of this work. Specifically, it was shown that, although significant work has been carried out in developing analysis methods for BTT data, little research has been published concerning the development of techniques for the analysis of data from assemblies undergoing two simultaneous synchronous (or one synchronous and one asynchronous) resonances. Part I of the paper describes a class of methods devised specifically to address this problem. The methods are based on an autoregressive curve-fit of the BTT data, designed specifically to identify two or more modes, either damped or undamped. In order to minimise the number of BTT probes required, an exact version of the curve-fit was developed, based on the assumption that the motion is the superposition of two sine waves of different frequencies, phases, and amplitudes. The new methods were validated using a mathematical BTT data simulator. It was shown that the techniques that include instrumental variable curve-fits perform best on this type of data.

In Part II of this work the new methods will be applied to BTT data from an experimental test rig. The rig was specifically designed to produce high quality BTT data from synchronous resonances. First, the design of the rig will be presented. Then, the results from the application of the methods to experimental data will be presented and analysed.

\section{BTT EXPERIMENTAL TEST RIG}

The basis of the BTT rig was a fan test rig consisting of a $1.22 \mathrm{~m}$ diameter tunnel, a drive motor, and a fan assembly with 8 blades. The blades were made of glass reinforced nylon (GRN) material, rated to 1800 revolutions-perminute (RPM), for which finite element data on the first six blade modes were available. Strain gauges connected to a 24channel slip ring and up to ten fibre-optic BTT probes were used for data acquisition.

The objective of the experimental rig was to provide synchronous blade tip timing data at very low cost in order to 


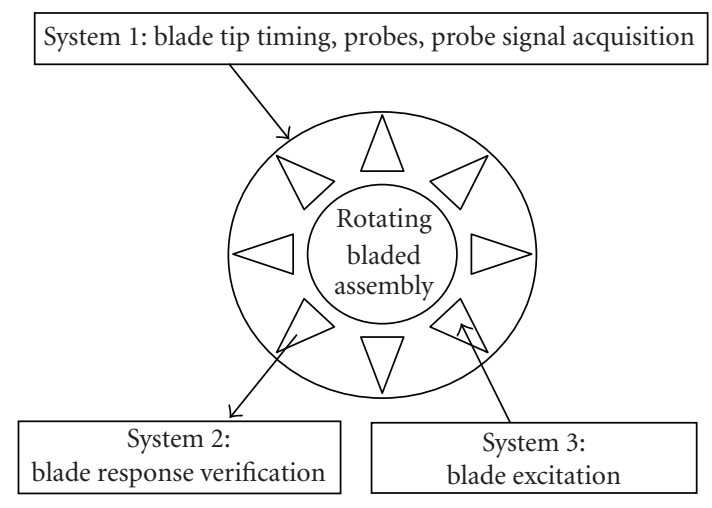

FIGURE 1: Conceptual design for BTT experimental rig.

select and validate the most promising data analysis formulations developed for the analysis of BTT data from simultaneous synchronous resonances.

The rig contained three basic systems.

(1) A blade tip timing data acquisition system.

(2) A blade response verification system.

(3) A blade excitation system.

The concept of the rig is summarised in Figure 1. The following decisions on the hardware options for each system were made.

(1) Blade tip timing system.

(a) Probe type: fibre-optic spot probes. The probes do not use lenses at either end, giving a typical spot size of a bout $2 \mathrm{~mm}$ for typical blade clearances (Heath and Imregun [1]).

(b) Probe signal generators: infrared light emitting diode (LED) fibre-optic transmitters with a wavelength of $850 \mathrm{~nm}$.

(c) Probe signal acquisition.

(i) Signal conditioning box: amplification followed by 8-bit analog-to-digital converter in the range zero to +2.5 volts.

(ii) Determination of blade tip time-of-arrival: complex programmable logic device (CPLD).

(iii) Data storage: personal computer hard drive.

(2) Blade frequency response verification system: strain gauge signals transmitted via a slip ring.

(3) Blade excitation system: inlet flow distortion.

Figure 2 shows an external view of the rig set-up: in the foreground are the probes attached by simple screw fittings to the assembly casing (along the same axial line) directly above the blade tips. The flexible armoured cables of the probes feed into the external signal conditioning box that contains an 8bit analog-to-digital converter on each channel. Then each probe's digital signal is passed directly into the custom-built BTT acquisition board in the personal computer. Above the computer is the digital oscilloscope and in the background is the tunnel inlet.

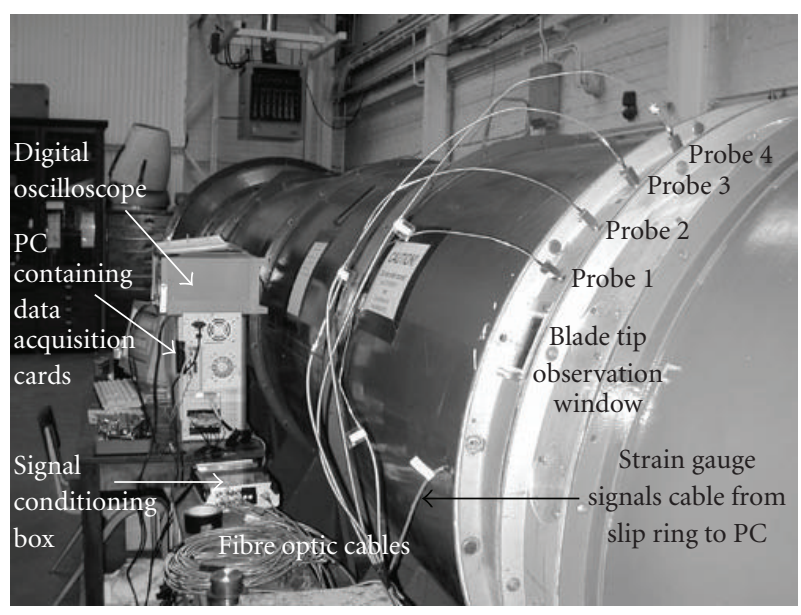

FIgURE 2: External view of the BTT experimental rig.

Figure 3(a) shows the blade arrangement in the rig, the strain gauges attached to some of the blades, and the slip ring used to receive the signal from the strain gauges. The slip ring was cooled by compressed air. Other features of the rig shown in Figure 3(a) are the trusses used to support different arrangements of blocker panels, and a set of windows cut on the casing to allow the visualisation of the blade tips. The windows were fitted with transparent Perspex panels that were tightly bolted to the rig casing.

Figure 3(b) shows some of the probe holes and the position of the once-per-revolution (OPR) marker. The marker served as a datum for the once-per-revolution sensor that was used to measure the rig's shaft speed. The sensor was a simple magnetic pickup device mounted at a distance of about $2 \mathrm{~mm}$ from the shaft on a plasticine support which provided a suitably secure and highly damped support medium.

A strain gauge (SG) and slip ring system were used to verify the frequencies of vibration of the blades during testing. Two of the blades were fitted with strain gauges, the signals from which passed through the slip ring to the data acquisition computer.

The fan assembly comprised eight glass reinforced nylon blades attached to a mild steel hub. The assembly radius was $0.61 \mathrm{~m}$. Each airfoil-section blade was $0.44 \mathrm{~m}$ long, with blade root chord of $0.085 \mathrm{~m}$ tapering to $0.075 \mathrm{~m}$ at the tip, with $11^{\circ}$ in-built twist. The stagger angle at the root was set to $40^{\circ}$, which transformed into a $29^{\circ}$ stagger angle at the blade tip due to the twist.

The modal characteristics of the blade were obtained from impact hammer tests (Carrington [2]) at 0 RPM and the manufacturer's finite element model. Table 1 compares the experimentally acquired natural frequencies with those predicted by finite element analysis at 0 RPM. Only the first 4 modes were tested.

The true natural frequencies of the blades at different rotational speeds were obtained from the strain gauge measurements and are plotted in the Campbell diagram of Figure 4 . The diagram plots the blade mode frequencies on 


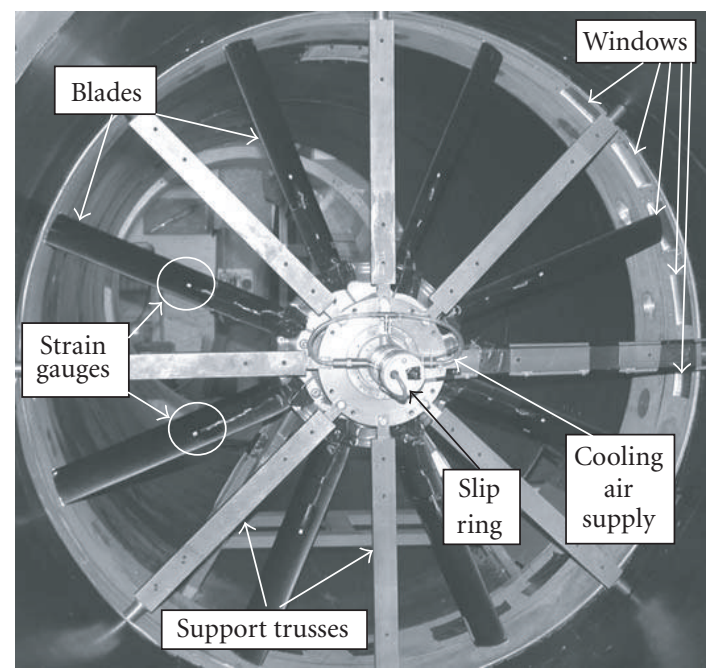

(a)

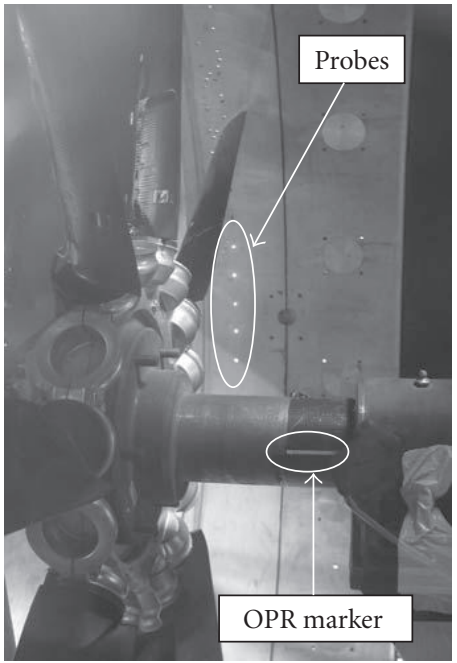

(b)

FIgURE 3: Internal views of BTT rig.

TABLE 1: Comparison of glass reinforced nylon blade natural frequencies from impact hammer test experiments and FE model data.

\begin{tabular}{l|cccccc}
\hline & $\begin{array}{l}\text { Mode 1 } \\
\text { 1st flap }\end{array}$ & $\begin{array}{l}\text { Mode 2 } \\
\text { 2nd flap }\end{array}$ & $\begin{array}{l}\text { Mode 3 } \\
\text { 3rd flap }\end{array}$ & $\begin{array}{l}\text { Mode 4 } \\
\text { 1st torsion }\end{array}$ & $\begin{array}{l}\text { Mode 5 } \\
\text { 4th flap }\end{array}$ & $\begin{array}{l}\text { Mode 6 } \\
\text { 2nd torsion }\end{array}$ \\
\hline Modal test & $17 \mathrm{~Hz}$ & $75 \mathrm{~Hz}$ & $84 \mathrm{~Hz}$ & $101 \mathrm{~Hz}$ & N/A & N/A \\
\hline FE model & $15.1 \mathrm{~Hz}$ & $72.4 \mathrm{~Hz}$ & $96.2 \mathrm{~Hz}$ & $118.0 \mathrm{~Hz}$ & $197.6 \mathrm{~Hz}$ & $281.1 \mathrm{~Hz}$ \\
\hline
\end{tabular}

the vertical axis, and the assembly rotational speed on the horizontal axis. The engine order (EO) lines showed range from $1 \mathrm{EO}$ to $20 \mathrm{EO}$ (dashed lines). The diagram shows variation of the natural frequencies for the first three bending modes, or flap modes, of the blades (solid lines). The zero speed frequency values are those obtained from the static modal analysis of the blades. It is possible to appreciate the increase in natural frequencies with rotational speed due to centrifugal stiffening and aerodynamic effects. At points where the engine order lines intersect the blade mode lines, resonances can occur. Inspection of the Campbell diagram indicates that simultaneous excitation of the first and second flap modes is possible between 650 and 700 RPM. In this speed range, the $2 \mathrm{EO}$ line crosses the first flap mode line at 650 RPM, and the $8 \mathrm{EO}$ line crosses the second flap mode line at 690 RPM. This is the speed range in which most of the testing took place.

The blades were excited using inlet flow blockages to disturb the pressure patterns acting over the fan. This technique was chosen for its simplicity and low cost. Meyer et al. [3] produced one of the first studies of the use of inlet distortions to excite aero-engine compressors. According to Meyer et al. [3] the greatest effect of blocking occurs when the engine order of vibration is divisible by the number of blocks, with maximum effects when the order of vibration is equal to the number of blocks. Despite its simplicity, the method is effective and is still being used; see, for example, [4]. The blocks used for the present work were wooden panels mounted on the assembly's support struts. Figure 5 shows the diagram of the chosen blocker pattern used in Figure 5(a), and the power spectral density (PSD) plot of the resulting response of blade 1. It is clear that the blade is responding at two distinct frequencies, approximately $20 \mathrm{~Hz}$ and $95 \mathrm{~Hz}$, corresponding to engine orders of 2 and 8 . With this 8 panel configuration the total inlet area was reduced by about $40 \%$.

\section{DATA POSTPROCESSING}

Postprocessing of BTT data is necessary prior to proceeding to the analysis of the data. All the postprocessing and analysis programs used in the BTT rig were designed for off-line use. The two functions of the postprocessing stage are as follows.

(i) To identify surplus or missing blade readings in the data file and to correct the BTT data accordingly.

(ii) To process the timing information into blade displacements.

More details on the postprocessing stage of the data collection procedure are given by Carrington [2] and GallegoGarrido [5].

\section{BTT DATA ANALYSIS}

In this section, data acquired from the experimental rig is analysed using the new multifrequency methods. The results from the BTT analysis are compared with SG results for the validation of the estimated blade response frequencies. 


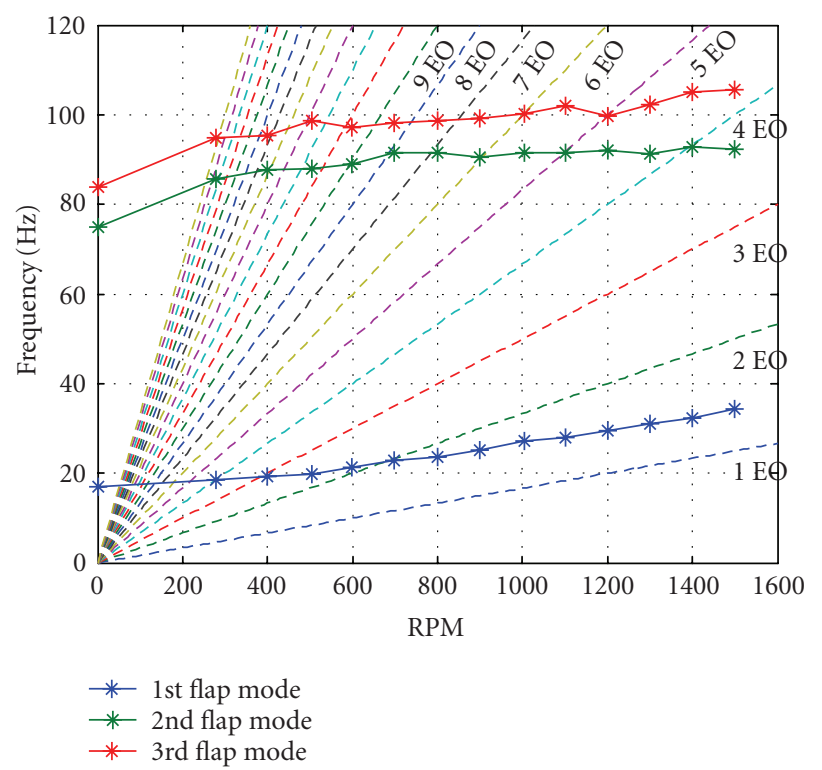

Figure 4: BTT rig fan Campbell diagram.

The methods were tested under two different resonant situations:

(i) a single synchronous resonance,

(ii) two simultaneous synchronous resonances.

The methods used in this experimental evaluation are those which showed best performance in Part I of this work, that is, MGAR, MGARIV, MGARES, and MGARIVES. The numerical simulation results presented in Part I show that the performance of the MAR, MARES, MAREP, and MGARMA was not satisfactory. Therefore, these latter approaches will not be considered for the experimental tests. Additionally, MGARES and MGARIVES produced almost identical results to MGAREP and MGARIVEP under most circumstances. Therefore, the latter were not included in the present experimental verification.

Results will be shown for the frequencies and amplitudes of the individual blades, for both the single and double resonance cases. The mean and standard deviation (STD) across the blades will be shown to give an indication of the accuracy of the estimates. It must be borne in mind that it is not the intention to recover an all-blade frequency since, in the presence of high levels of mistuning, the results from all-blade formulations can be wrong.

\subsection{Single resonance case: $2 E O$ excitation}

This case is intended to show that the two-degree-of-freedom methods developed in Part I are general enough to work for cases were there is only a single synchronous resonance in the BTT data. The test configuration is given in Table 2. A low PSR setting was used to evaluate the methods in extreme conditions. The assembly's rotational speed was increased slowly during the test from 606 to 684 RPM.
TABLE 2: Single resonance experimental test configuration.

\begin{tabular}{l|ccc}
\hline $\begin{array}{l}\text { Excitation } \\
\text { engine order }\end{array}$ & PSR \% & No probes & $\begin{array}{l}\text { Approx. speed } \\
\text { range RPM }\end{array}$ \\
\hline 2 & 20 & 9 & $600-690$ \\
\hline
\end{tabular}

To achieve a $2 \mathrm{EO}$ only resonance a different set of flow blockages was used, as shown in Figure 6. The inlet blockage layout consisted of two 2EO blockers, yielding blade responses at a single frequency corresponding to $2 \mathrm{EO}$.

The 2EO excitation case features a single resonant frequency but enough probes were used to allow the application of multifrequency methods to recover up to 2 engine orders. The objective was to assess how accurately the multifrequency approaches recovered the frequency of the only resonance present in the data. The estimates for the second frequency are not presented.

The BTT frequency results were compared to the results from the strain gauge system. Figure 7 is the Z-plot from a 2EO excitation case performed in similar conditions as the case shown in Table 2. A Z-plot is a plot of the value of the power spectral density obtained from the SG data at different frequencies and for increasing speed of rotation. The amplitude of the power spectral density is denoted using colour, red being high and blue low. The plot shows that there is a single significant resonance at a frequency increasing from $18 \mathrm{~Hz}$ at $570 \mathrm{RPM}$ to $27 \mathrm{~Hz}$ at $720 \mathrm{RPM}$.

Figure 8 shows the frequencies recovered from the MGAR and MGARIV methods plotted on the assembly's Campbell diagram. It can be seen that both methods yield estimates that lie on the 2EO line and are in good agreement with the strain gauge measurements.

Table 3 shows the engine order estimates obtained from all the tested BTT data analysis methods. Notice that, for this case, blades 2, 4, and 5 have not yielded answers in the chosen RPM range due to missing blade events. The most likely cause for these events is a misalignment of the blades (e.g., the stagger angle may have not been set correctly for these three blades). The grey boxes denote estimates that are outside the acceptable engine order range (i.e., true engine order \pm 0.5 ). The last two rows of the table show the mean and standard deviation of the engine order estimates obtained over all the blades for each of the methods. This averaging may not be entirely valid as it is possible that the assembly is mistuned, that is, that the blades are truly responding at slightly different frequencies. Nevertheless, as the blade modes are well separated, it is certain that all the blades are responding to the same engine order excitation.

Table 3 shows that the multifrequency methods were able to recover the sought engine order with a high degree of accuracy despite having been specifically designed to operate in the presence of two simultaneous resonances. MGARES performs better than the other methods in terms of both bias and standard deviation (STD). MGARIVES exhibits slightly higher mean error and scatter but the difference to the MGARES results is not significant. The MGAR and MGARIV methods feature the highest scatter due to bad estimates for blade 6 . 


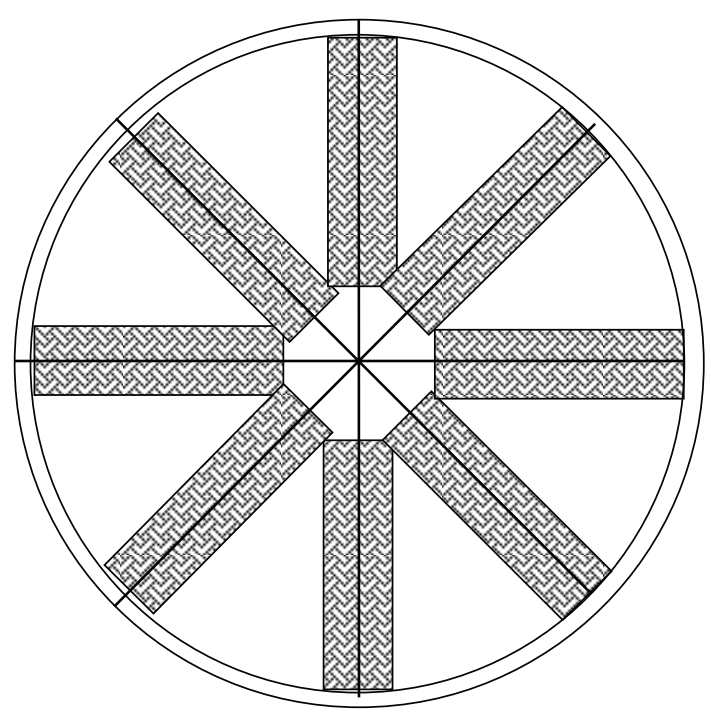

(a)

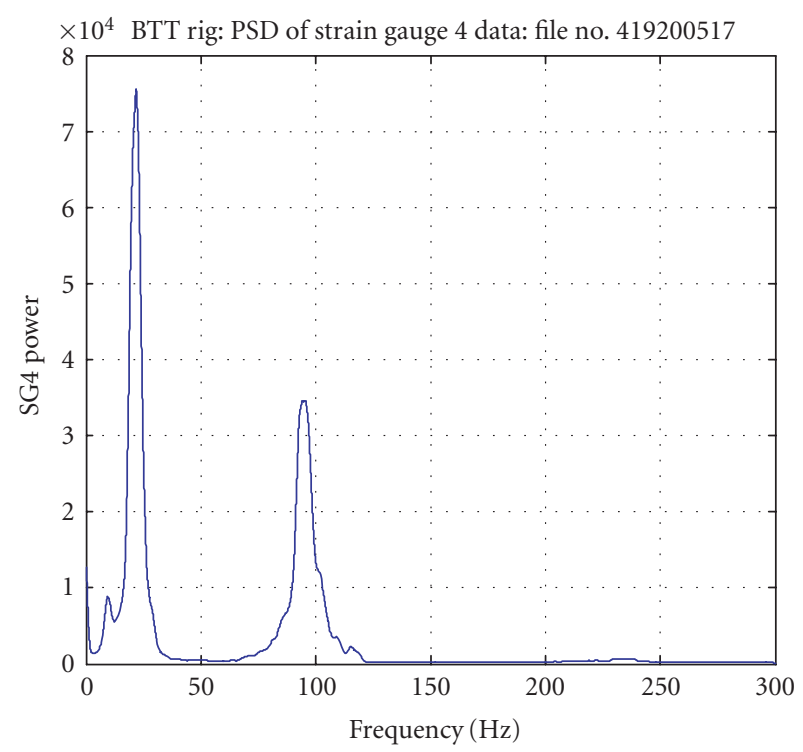

(b)

FIGURE 5: Eight 8 EO blockers (a) and power spectral density of resulting blade response (b).

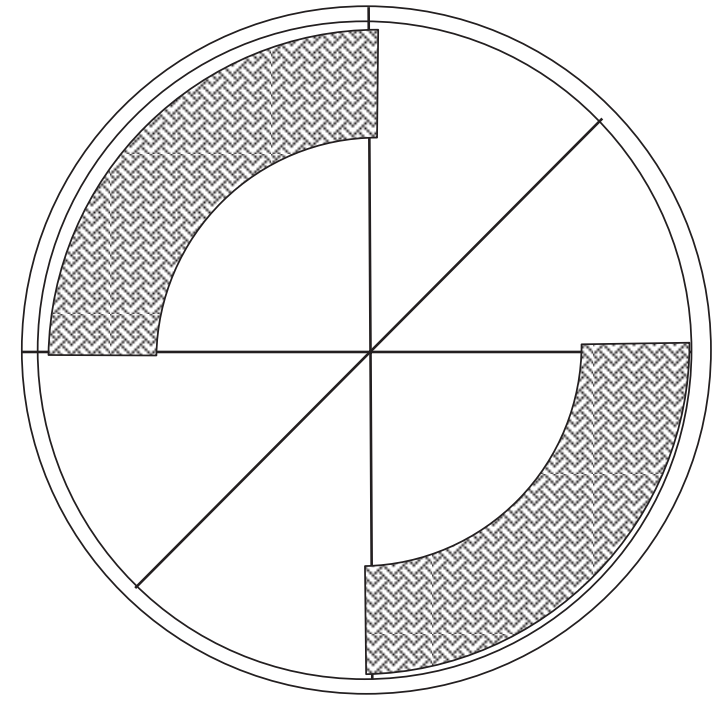

(a)

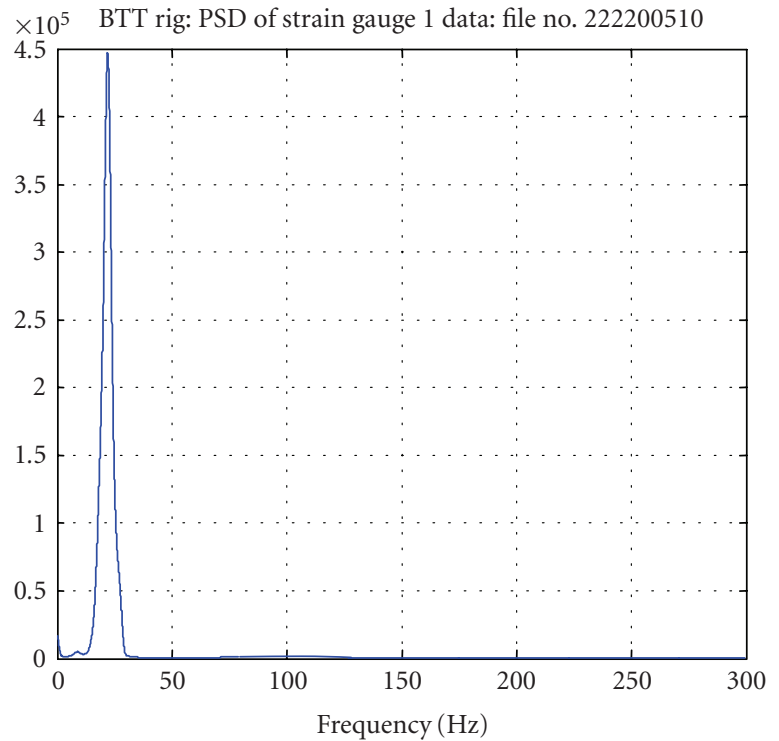

(b)

FIGURE 6: Two 2EO blockers (a) and power spectral density of resulting blade response (b).

\subsection{Double resonance case: $2 E O$ and $8 E O$ excitations}

In this case, the performance of the methods on an assembly undergoing two simultaneous synchronous resonances is described and assessed. The simultaneous excitation of two modes was produced by means of 8 blockages as already shown in Figure 5. The Z-plot in Figure 9 shows that two resonances are occurring simultaneously between 600 and 800 RPM. As already discussed, these are caused by $2 \mathrm{EO}$ and $8 \mathrm{EO}$ excitations. The frequency at which the first mode responds at high amplitude ranges from 20 to $27 \mathrm{~Hz}$ as before. The second mode responds at high amplitude in the range from 80 to $120 \mathrm{~Hz}$.

The test parameters for this case are shown in Table 4. The PSR is based on the $2 \mathrm{EO}$ resonance and is equal to $40 \%$. The rotational speed range is wider than in the single resonance case. BTT data from nine probes is available.

Figure 10 shows the frequency estimates obtained from the MGAR, MGARIV, MGARIVEP, and MGARIVES methods plotted on the assembly's Campbell diagram. It can be 


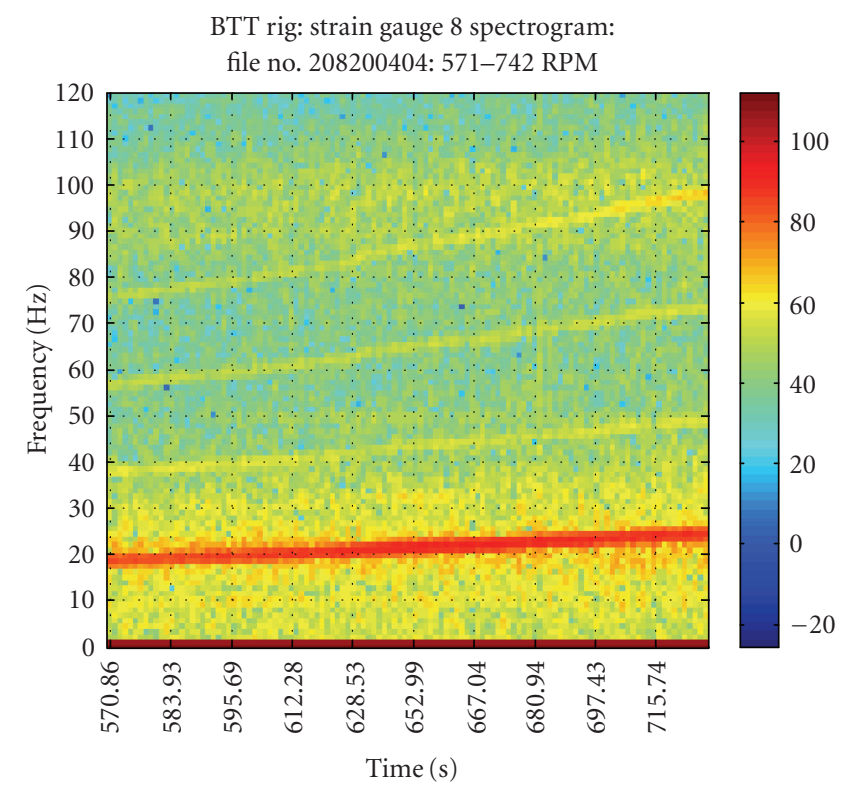

FIGURE 7: Frequency-speed plot for single resonance case from SG data.

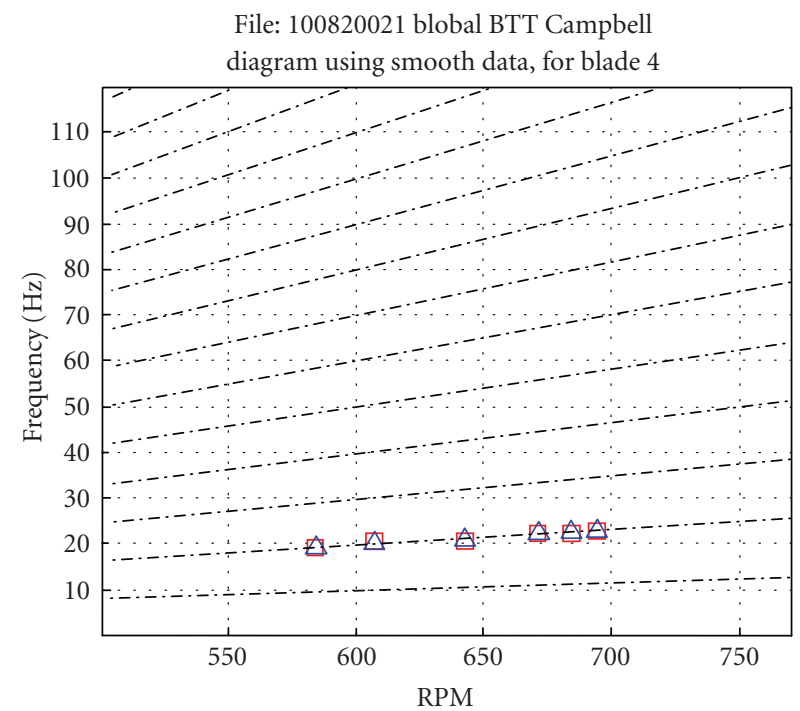

$\square$ MGARIV

$\triangle$ MGAR

FIgURE 8: Single resonance case: Campbell diagram constructed from BTT multidegree of freedom analysis.

seen that all methods recovered frequency values that were in good agreement with the strain gauge estimates throughout the tested RPM range.

The engine order results for the first blade mode are shown in Table 5. The table shows that MGARES recovered results within the error bound for all the blades, featuring the lowest variation across the blades. Using the same arguments, the next best method is MGARIVES, followed by the MGARIV and MGAR.
TABLE 3: 2EO case: blade-by-blade engine order estimates.

\begin{tabular}{l|cccc}
\hline Blade & MGAR & MGARIV & MGARES & MGARIVES \\
\hline 1 & 2.16 & 2.16 & 2.04 & 2.06 \\
\hline 3 & 2.01 & 2.00 & 1.93 & 1.92 \\
\hline 6 & 2.95 & 3.22 & 2.35 & 2.48 \\
\hline 7 & 2.35 & 2.33 & 2.21 & 2.24 \\
\hline 8 & 2.38 & 2.39 & 2.18 & 2.19 \\
\hline Mean & $\mathbf{2 . 3 7}$ & $\mathbf{2 . 4 2}$ & $\mathbf{2 . 1 4}$ & $\mathbf{2 . 1 8}$ \\
\hline STD & $\mathbf{0 . 3 6}$ & $\mathbf{0 . 4 7}$ & $\mathbf{0 . 1 6}$ & $\mathbf{0 . 2 1}$ \\
\hline
\end{tabular}

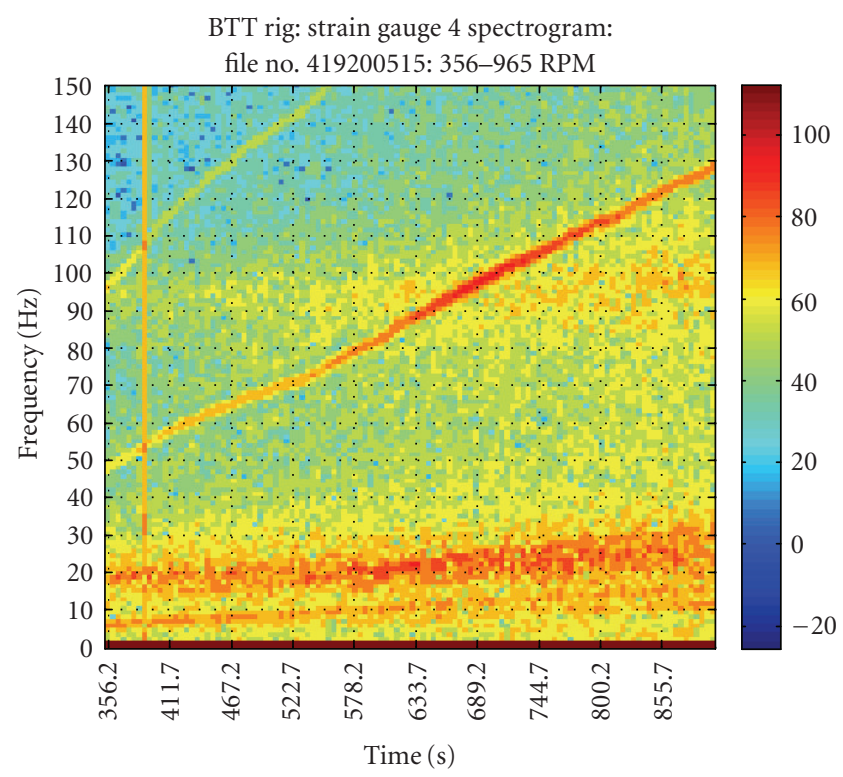

FIGURE 9: Frequency-speed plot for double resonance case from SG data.

TABle 4: Double resonance experimental test configuration.

\begin{tabular}{lccc}
\hline $\begin{array}{l}\text { Excitation } \\
\text { engine order }\end{array}$ & PSR \% & No probes & $\begin{array}{l}\text { Approx. speed } \\
\text { range RPM }\end{array}$ \\
\hline 2,8 & 40 & 9 & $600-800$ \\
\hline
\end{tabular}

The results for the second mode are shown in Table 6 . It can be seen that all the methods failed for blade 5. For the other blades, all the engine order estimates are accurate apart from the MGARIVES estimate for blade 7. As with the first blade mode, the most consistent estimates for the second blade mode were obtained from MGARES.

All the methods presented have managed to retrieve two simultaneous frequencies from the analysis of BTT data. Some of the methods have achieved this more successfully than others, but in general the results are in good agreement with the frequency estimates obtained from the strain gauge measurements.

In the example shown, MGARES appears to be the most robust methods for the analysis of simultaneously occurring resonances in experimental BTT data. MGARIVES is the next 


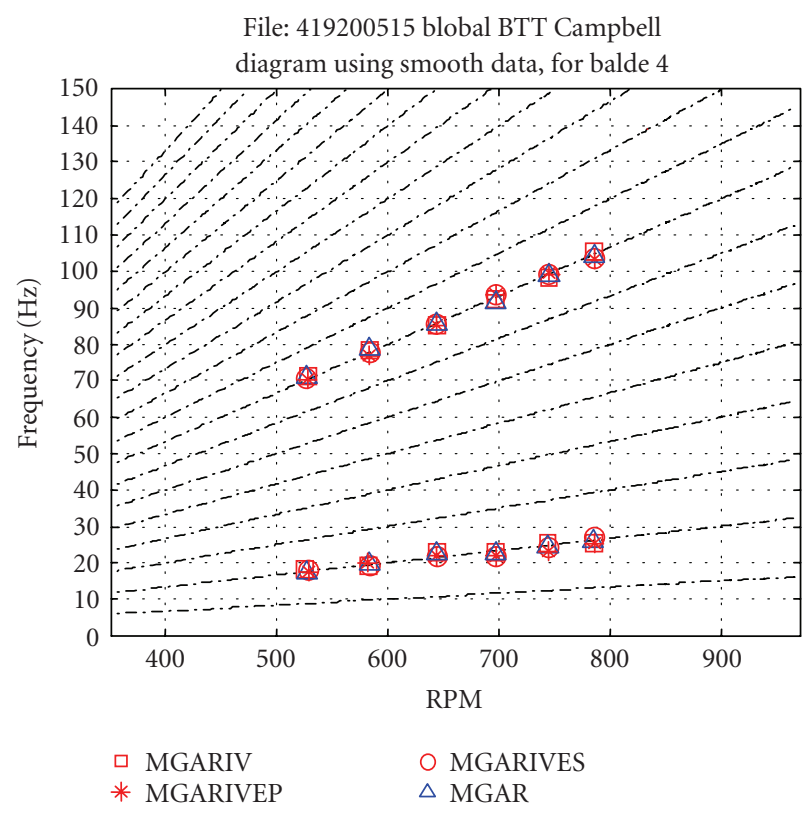

FIgURE 10: Double resonance case: Campbell diagram constructed from multidegree of freedom BTT analysis.

TABLE 5: 2EO and 8EO case: the first blade mode frequencies $(\mathrm{Hz})$ recovered by BTT methods.

\begin{tabular}{l|cccc}
\hline Blade & MGAR & MGARIV & MGARES & MGARIVES \\
\hline 1 & 2.26 & 2.32 & 2.15 & 2.36 \\
\hline 2 & 0.6 & 2.05 & 2.12 & 2.18 \\
\hline 3 & 1.80 & 1.75 & 1.72 & 1.22 \\
\hline 4 & 1.96 & 1.98 & 1.79 & 1.87 \\
\hline 5 & 1.46 & 1.18 & 1.67 & 1.69 \\
\hline 6 & 2.38 & 2.43 & 1.99 & 2.23 \\
\hline 7 & 3.27 & 3.30 & 2.41 & 2.56 \\
\hline Mean & $\mathbf{1 . 9 8}$ & $\mathbf{2 . 1 3}$ & $\mathbf{1 . 9 9}$ & $\mathbf{1 . 9 7}$ \\
\hline STD & $\mathbf{0 . 7 7}$ & $\mathbf{0 . 6 1}$ & $\mathbf{0 . 2 5}$ & $\mathbf{0 . 4 4}$ \\
\hline
\end{tabular}

best method, with slightly higher scatter in the results. However, the differences do not appear to be significant.

The performance of the methods in recovering the engine order from the second blade mode is better than from the first. The SG data Z-plot of Figure 9 shows that the first mode response covers a broad frequency spectrum. This, in turn, has caused a higher scatter engine order estimates.

\section{AMPLITUDE ESTIMATION}

Once the engine order (and/or frequency of vibration) has been estimated, the amplitude of vibration can be obtained. The blade tip motion is assumed to be a linear summation of $J$ sinusoids. When $J$ frequencies are considered to be present in the blade tip response the following relationship applies to
TABLE 6: 2EO and 8EO case: the second blade mode frequencies (in $\mathrm{Hz}$ ) recovered by BTT methods.

\begin{tabular}{l|cccc}
\hline Blade & MGAR & MGARIV & MGARES & MGARIVES \\
\hline 1 & 8.32 & 8.41 & 8.24 & 8.41 \\
\hline 2 & 7.80 & 7.80 & 8.02 & 8.37 \\
\hline 3 & 8.15 & 8.45 & 7.96 & 8.32 \\
\hline 4 & 8.42 & 8.24 & 8.44 & 8.49 \\
\hline 5 & - & - & - & 9.25 \\
\hline 6 & 8.21 & 8.24 & 8.27 & 8.03 \\
\hline 7 & 8.49 & 7.88 & 8.34 & 8.81 \\
\hline 8 & 8.11 & 8.22 & 7.61 & 7.58 \\
\hline Mean & $\mathbf{8 . 2 1}$ & $\mathbf{8 . 1 8}$ & $\mathbf{8 . 1 3}$ & $\mathbf{8 . 2 9}$ \\
\hline STD & $\mathbf{0 . 2 3}$ & $\mathbf{0 . 2 5}$ & $\mathbf{0 . 2 8}$ & $\mathbf{0 . 3 9}$ \\
\hline
\end{tabular}

the blade tip displacements:

$$
y_{i}=A_{0}+\sum_{m=1}^{J} A_{m} \sin \left(\omega_{m} t_{i}\right)+B_{m} \cos \left(\omega_{m} t_{i}\right),
$$

where $y_{i}$ is the measured displacement, $t_{i}$ is the time at which the displacement was calculated, $\omega_{m}$ are the frequencies of vibration of the sinusoidal components, $A_{0}$ is a constant offset, and $A_{m}, B_{m}$ are the amplitudes of the sine and cosine terms.

Having values for the frequencies and the blade displacements and corresponding times allows the calculation of the unknown amplitudes. Equation (1) is expanded as

$$
\begin{gathered}
{\left[\begin{array}{cccccc}
1 & \sin \left(\omega_{1} t_{1}\right) & \cos \left(\omega_{2} t_{1}\right) & \cdots & \sin \left(\omega_{J} t_{1}\right) & \cos \left(\omega_{J} t_{1}\right) \\
1 & \sin \left(\omega_{1} t_{2}\right) & \cos \left(\omega_{2} t_{2}\right) & \cdots & \sin \left(\omega_{J} t_{2}\right) & \cos \left(\omega_{J} t_{2}\right) \\
\vdots & \vdots & \vdots & \vdots & \vdots & \vdots \\
1 & \sin \left(\omega_{1} t_{N}\right) & \cos \left(\omega_{2} t_{N}\right) & \cdots & \sin \left(\omega_{J} t_{N}\right) & \cos \left(\omega_{J} t_{N}\right)
\end{array}\right]} \\
\quad\left[\begin{array}{c}
A_{0} \\
A_{1} \\
B_{1} \\
\vdots \\
A_{J} \\
B_{J}
\end{array}\right]=\left[\begin{array}{c}
y_{1} \\
y_{2} \\
\vdots \\
y_{N}
\end{array}\right]
\end{gathered}
$$

and the unknown amplitudes are calculated either by direct inversion of the data matrix or in a least squares sense if there are more blade tip measurements than unknown coefficients. The total amplitudes for each of the modes, $\hat{A}_{m}$, can now be calculated using the simple relationship:

$$
\widehat{A}_{m}=\sqrt{A_{m}^{2}+B_{m}^{2}}
$$

and the phases by

$$
\phi_{m}=\operatorname{atan}\left(\frac{B_{m}}{A_{m}}\right) .
$$

For the $2 \mathrm{EO}$ and $8 \mathrm{EO}$ case, the estimated amplitudes for blade mode 1 are given in Table 7 and for blade mode 2 in 
TABLE 7: The first blade mode peak-to-peak amplitudes ( $\mathrm{mm}$ ) recovered by BTT methods.

\begin{tabular}{l|cccc}
\hline Blade & MGAR & MGARIV & MGARES & MGARIVES \\
\hline 1 & 7.70 & 7.63 & 7.84 & 7.60 \\
\hline 2 & 14.40 & 7.34 & 7.45 & 7.47 \\
\hline 3 & 6.61 & 6.69 & 6.78 & 8.50 \\
\hline 4 & 9.63 & 9.64 & 9.48 & 9.54 \\
\hline 5 & 10.81 & 12.61 & 10.02 & 9.95 \\
\hline 6 & 6.95 & 6.92 & 7.01 & 6.98 \\
\hline 8 & 6.24 & 6.28 & 6.83 & 6.72 \\
\hline
\end{tabular}

TABLE 8: The second blade mode peak-to-peak amplitudes (mm) recovered by BTT methods.

\begin{tabular}{lcccc}
\hline Blade & MGAR & MGARIV & MGARES & MGARIVES \\
\hline 1 & 4.87 & 4.92 & 4.92 & 4.97 \\
\hline 2 & 5.16 & 5.21 & 5.21 & 5.07 \\
\hline 3 & 3.81 & 3.88 & 3.86 & 3.73 \\
\hline 4 & 5.24 & 5.25 & 5.26 & 5.27 \\
\hline 5 & - & - & - & 5.21 \\
\hline 6 & 4.16 & 4.14 & 4.16 & 4.48 \\
\hline 8 & 4.70 & 4.70 & 5.29 & 5.13 \\
\hline
\end{tabular}

Table 8. The amplitudes have been calculated using the unrounded engine order estimates from each analysis method. The numbers tabulated are peak-to-peak amplitudes, that is, $2 \hat{A}_{m}$. Notice that, as the assembly's rotational speed is increased, the blade tip response amplitudes will change. The amplitude values in Tables 7 and 8 were calculated for an assembly speed of 700 RPM.

Both tables show that there are significant differences in the vibration amplitudes of each blade. This is an indication that the assembly is mistuned. Furthermore, as the frequency estimation methods were in good agreement, the recovered amplitudes obtained from all the methods are also very similar for individual blades. The engine order estimated by the MGAR method caused a suspect value for the amplitude of the second blade in Table 7 .

The amplitude estimates for blade mode 2 are in even better agreement with each other for individual blades. Notice that the second mode amplitudes of vibration are lower than those of the first blade mode, as expected from the power spectral density of the strain gauge signals (Figure 5).

The amplitude results for the double resonance case could not be experimentally verified. However, they serve to show that the variation in engine order (and hence response frequency) estimates obtained from each of the methods (see Tables 5 and 6) has little effect in the calculation of the amplitude of vibration. The next section will demonstrate the experimental validation of amplitudes obtained for single resonance cases.
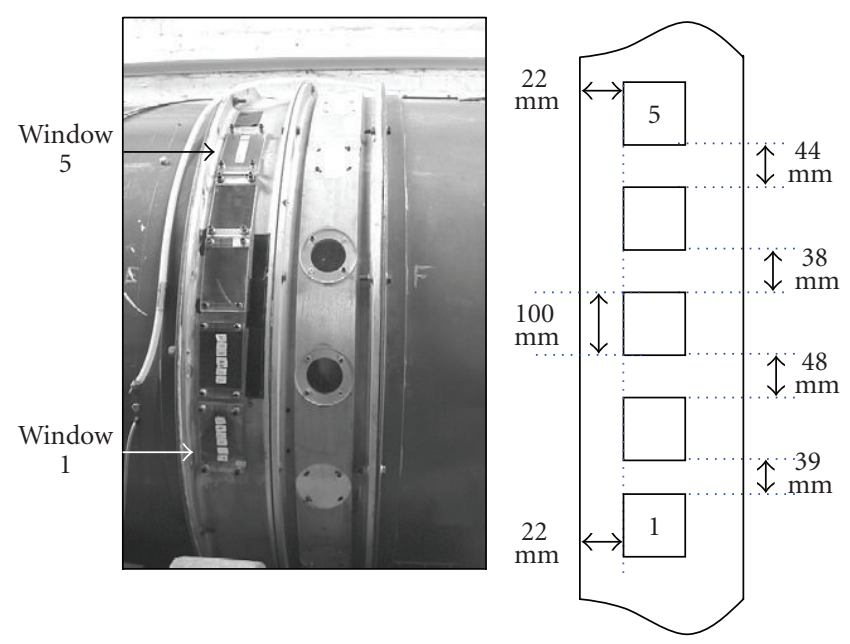

FIgURE 11: Rig casing with cut-out windows.

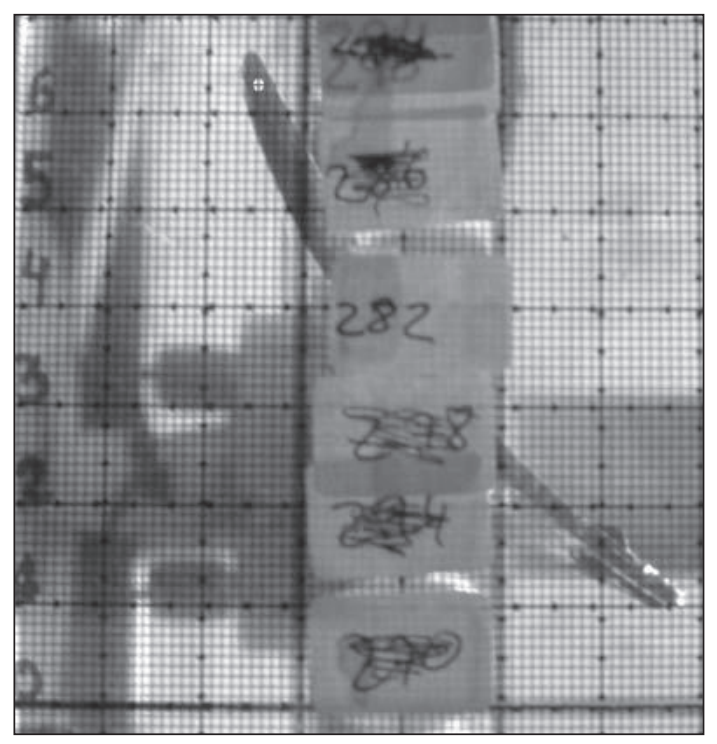

FIGURE 12: Typical visualization photo (digitally enhanced).

\section{AMPLITUDE VALIDATION}

A complete finite element model for the bladed assembly of the rig was not available; only the modal frequency predictions of the blade shown in Table 1 were provided by the manufacturer. Therefore, the validation of the amplitudes was carried out using a blade visualization methodology. Osburn [6] described an experiment in which the blade vibration was visualised on a compressor stage by means of a stroboscopic light synchronised with the tachometer, and the displacements were recorded using a photographic camera. This arrangement for visualising rotating bladed disks was first used in the early work by Campbell [7].

For the present work, a modified version of Osburn's methodology was used in order to validate the maximum 


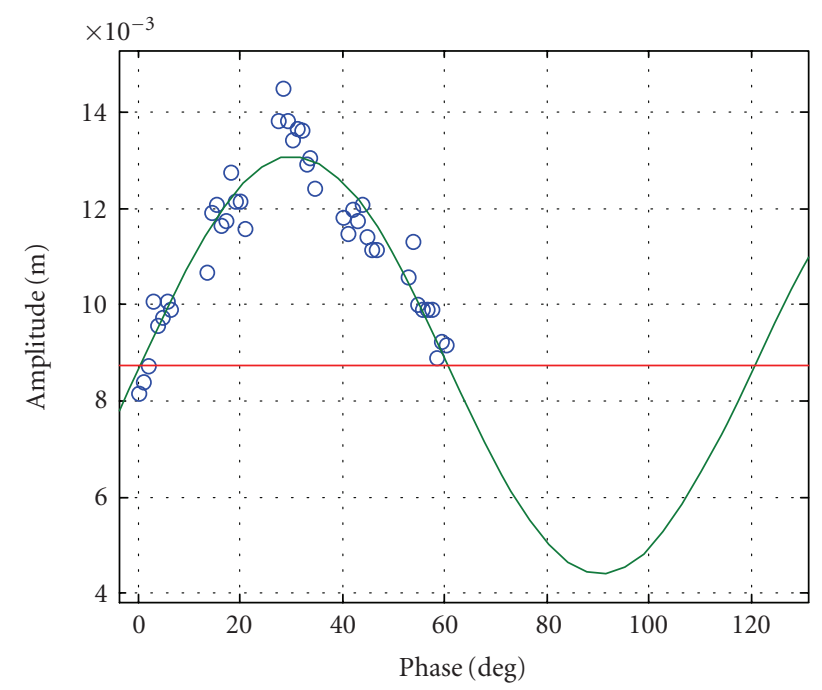

(a)

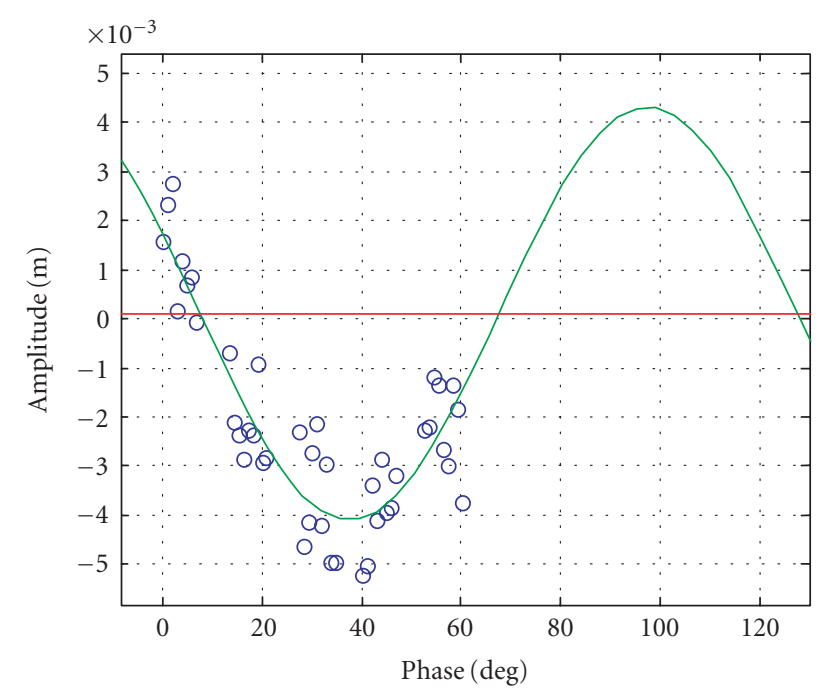

(b)

FIGURE 13: 3EO case normal and tangential visualised displacements and curve-fits.

TABLE 9: Amplitude validation test parameters.

\begin{tabular}{l|cccc}
\hline EO & PSR & Target RPM & $\begin{array}{l}\text { Visualisation } \\
\text { RPM }\end{array}$ & $\begin{array}{l}\text { BTT RPM range } \\
\text { on resonance }\end{array}$ \\
\hline 2 & $20 \%$ & 655 & $648-654$ & $635-660$ \\
\hline 3 & $30 \%$ & 385 & $384-390$ & $375-403$ \\
\hline
\end{tabular}

Table 10: Amplitude estimates (mm).

\begin{tabular}{l|cc}
\hline \multirow{2}{*}{} & \multicolumn{2}{|c}{ Predicted amplitudes (blade 6) } \\
\cline { 2 - 3 } & 2EO & 3EO \\
\hline Visualisation & 18.10 & 6.15 \\
\hline MGAR & 17.35 & 5.82 \\
\hline MGARIV & 16.22 & 5.99 \\
\hline MGARES & 17.81 & 6.21 \\
\hline MGARIVES & 18.28 & 6.59 \\
\hline
\end{tabular}

amplitudes recovered by the BTT data analysis methods (Gallego-Garrido and Dimitriadis [8]). The experimental set-up is based on the arrangement used by Osburn but the visualisation of the blade is performed at several points along the circumference of the casing. In this way a significant part of the response waveform is measured.

In order to film the blade tips, a series of windows were cut out of the rig's casing around the fan, and fitted with transparent Perspex panels. Figure 11 shows a photograph of the windows fitted on the casing. The arc of the casing covered by the windows was about $63.03 \mathrm{deg}$. This coverage was enough to visualise the point of maximum amplitude of the response waveform for responses to excitation frequencies equal to or higher than 2EO. The blade tip movements were recorded using a digital video camera set perpendicular to the window being observed.

In order to visualise the blades at exact time instances while rotating, a strobe light was connected to the BTT system. The arrangement was such that a delayed once-perrevolution pulse would trigger the strobe light. Figure 12 displays a typical photograph of the blade tip obtained during visualisation tests. Changing the strobe light trigger delay when the blade is rotating at a constant speed has the same effect as sweeping through the phase of the responsewaveform; therefore, the blade tip could be seen at different points along the casing.

During each test the fan was run at a constant speed. The test speeds were chosen from the rig's Campbell diagram and are shown in Table 9. Two test cases were used, one under 2EO excitation and one under 3EO. As the visualisation experiment was only capable of capturing single mode responses, double resonance cases were not considered.

The visualisation was carried out only on blade 6 . Figure 13 shows the blade tip displacement data obtained for the $3 \mathrm{EO}$ case in directions normal and tangential to the bladed assembly. It can be seen that exactly half the response waveform was covered by the visualisation windows. The total response amplitude was calculated as the vector addition of the response amplitudes in the two directions. Table 10 shows the response amplitude estimates obtained from visualisation and from several BTT data analysis methods. Notice that as the excitation case was different from the case that was used in Section 5 the results are not comparable. The larger blockers used to excite $2 \mathrm{EO}$ or $3 \mathrm{EO}$ only resulted in larger amplitude blade vibrations. Nevertheless, the table shows that there is a very good correlation between the amplitudes measured using visualisation and those obtained from the BTT data analysis methods. 


\section{CONCLUSIONS}

In this work, the problem of the analysis of BTT data from assemblies undergoing two simultaneous resonances has been addressed. A class of methods has been developed to extract frequency (engine order) and amplitude information from such data. These multifrequency methods have been tested on two sets of experimental BTT data, obtained from a purpose-built fan test rig.

The methods succeeded in estimating the correct frequency of vibration when applied to BTT data from a bladed assembly undergoing a single synchronous resonance. Furthermore, it has been shown that all the methods can recover the correct frequencies for the case when simultaneous $2 \mathrm{EO}$ and $8 \mathrm{EO}$ resonances are present in the data. The results obtained for the second mode were more consistent than those for the first mode. Estimates of the amplitude of vibration obtained using the frequencies recovered from the methods were in close agreement with each other and provided a clear indication of the mistuning present in the assembly tested.

The experimental validation of the methods shows that the most consistent approach is MGARES since all the engine order estimates it returned were within the acceptable range. Therefore, the main conclusion of the work presented here is that the recommended method for the analysis of BTT data from assemblies undergoing single or multiple simultaneous resonances is MGARES, provided that the PSR limits defined in Part I are respected.

\section{ACKNOWLEDGMENTS}

The authors would like to thank Rolls-Royce PLC and the Engineering and Physical Sciences Research Council of the UK.

\section{REFERENCES}

[1] S. Heath and M. Imregun, "A survey of blade tip-timing measurement techniques for turbomachinery vibration," Journal of Engineering for Gas Turbines and Power, vol. 120, no. 4, pp. 784791, 1998.

[2] I. B. Carrington, "Development of blade tip timing data analysis techniques," EngD thesis, Faculty of Science and Engineering, University of Manchester, Manchester, UK, 2002, submitted.

[3] A. J. Meyer, H. F. Calvert, and C. R. Morse, "Effects of obstructions in compressor inlet on blade vibration in 10-stage axialflow compressor," Tech. Rep. NACA RM E9L05, NASA Center, Washington, DC, USA, February 1950.

[4] R. M. Wallace, S. P. King, J. Kenyon, and W. F. O’Brien, “Modal response of a transonic fan blade to periodic inlet pressure distortion," in Proceedings of the 9th National Turbine Engine High Cycle fatigue (HCF) Conference, Pinehurst, NC, USA, March 2004.

[5] J. Gallego-Garrido, "Further developments of blade tip-timing data analysis techniques," EngD thesis, Faculty of Engineering and Physical Sciences, University of Manchester, Manchester, UK, 2005.

[6] N. G. Osburn, "Implementation of a two probe tip-timing technique to determine compressor blade vibrations," M.S. thesis, Naval Postgraduate School, Monterey, Calif, USA, 2000.
[7] W. Campbell, "The protection of steam-turbine disk wheels from axial vibration," Transactions of the American Society of Mechanical Engineers, vol. 46, no. 1920, pp. 31-160, 1924.

[8] J. Gallego-Garrido and G. Dimitriadis, "Validating synchronous blade vibration amplitudes from blade tip-timing data analysis," in Proceedings of the 8th International Conference on Vibrations in Rotating Machinery, vol. 2004-2, pp. 205-214, Swansea, UK, September 2004. 

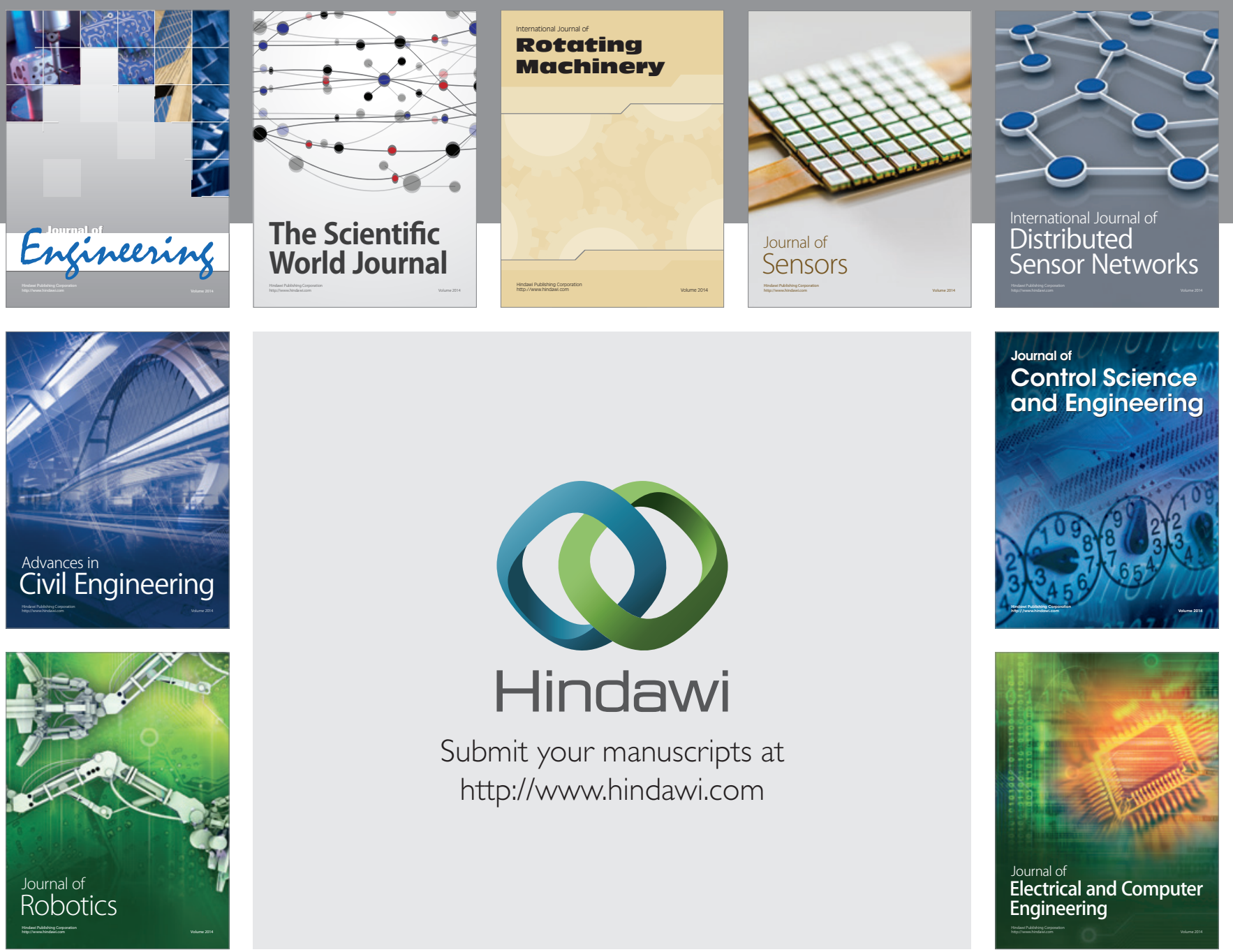

Submit your manuscripts at

http://www.hindawi.com
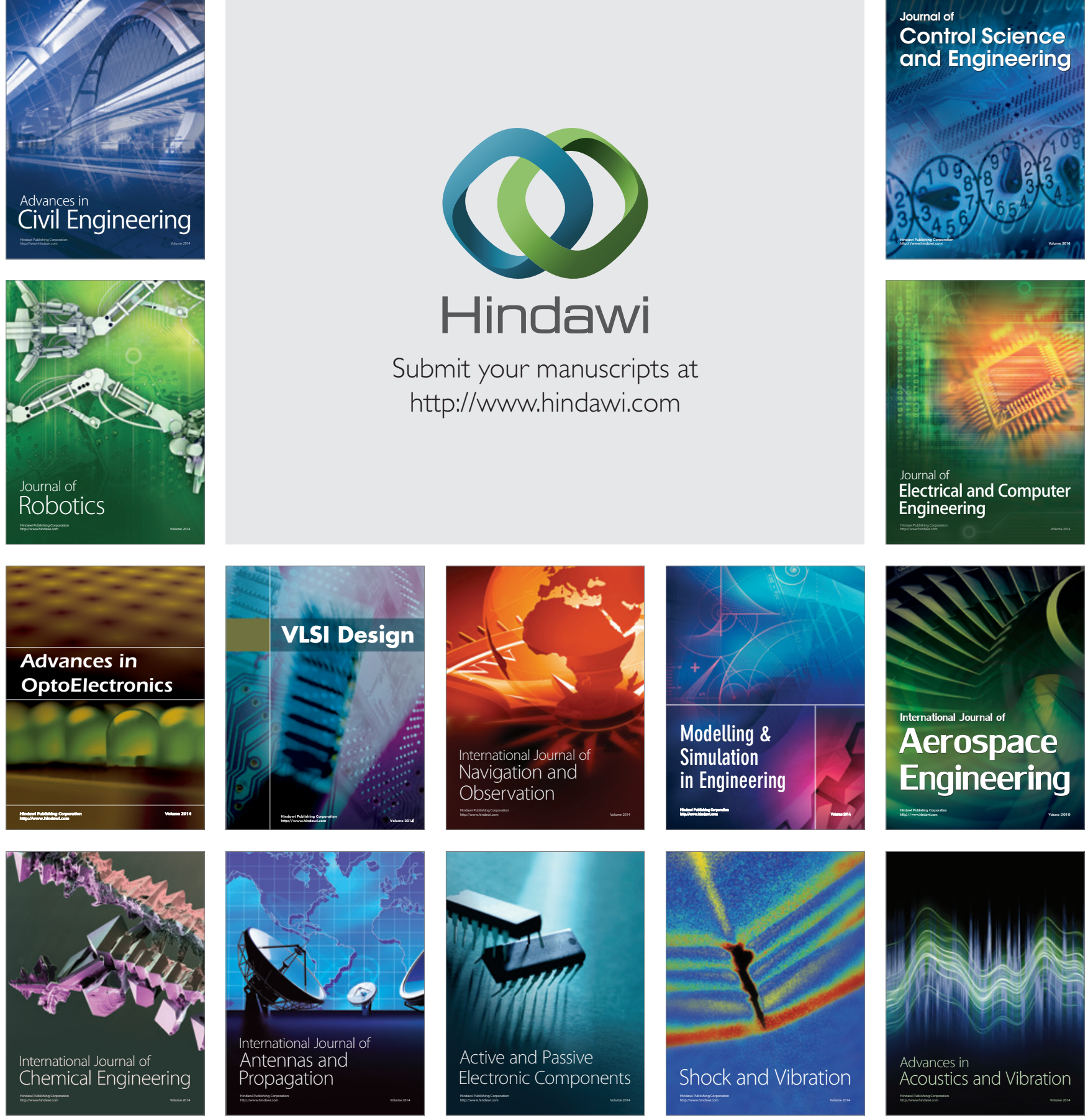